\title{
Formation of a basin-scale surface chlorophyll pattern by Rossby waves
}

\author{
Michio Kawamiya and Andreas Oschlies \\ Institut für Meereskunde an der Universität Kiel, Düsternbrooker Weg 20, D-24105, Kiel, Germany
}

\begin{abstract}
The enhancement of surface chlorophyll by Rossby waves, which has recently been detected in bandpassfiltered ocean color data [Cipollini et al., 2001; Uz et al.,, 2001], is shown to be intense enough to form a dominant pattern in monthly mean basin-scale ocean color satellite maps of the Indian Ocean. Results from a biological-physical coupled model suggest that this phenomenon, which is visible predominantly in austral winter, is caused by Rossby-wave induced upwelling that lifts the deep chlorophyll maximum (DCM) into contact with the surface mixed layer (ML). The model results suggest that these events are not associated with any significant input of nutrients into the ML. While the temporal enhancement of regional primary production by Rossby waves is substantial ( $\sim 30 \%)$, it is not necessarily associated with a corresponding increase in surface chlorophyll, e.g., when the ML is too shallow to touch the DCM, and may hence escape detectability by satellite measurements.
\end{abstract}

\section{Introduction}

The basin-scale (or global) pattern of the distribution of surface chlorophyll can often be satisfactorily explained by Ekman dynamics. Where the wind pattern is such that it exerts Ekman upwelling, high chlorophyll concentrations are expected and the reverse is true when it causes downwelling. Superimposed on this simple picture are disturbances by phenomena such as coastal upwelling, vertical mixing and eddy activities [Mann and Lazier, 1991]. Using band-pass filtered surface chlorophyll satellite data, Cipollini et al. [2001] and $U z$ et al. [2001] recently pointed out that Rossby waves also have an impact on upper ocean biology in the surface ocean. Although some possible mechanisms have been proposed (nutrient injection into the surface layer, uplift of subsurface chlorophyll to the surface), the restriction to satellite data made a detailed mechanistic description difficult. So far it is also unclear whether Rossby waves are contributing to form large-scale patterns of biological variables such as chlorophyll and primary production.

Figure la shows surface chlorophyll in the Indian Ocean in September 1998 measured by satellite (SeaWiFS). While the most notable feature here is the high concentration associated with coastal upwelling in the Arabian Sea (discussed elsewhere [Kawamiya and Oschlies, 2001]), another feature that draws attention is the belt of moderately high chlorophyll concentrations between $\sim 10^{\circ} \mathrm{S}$ and $20^{\circ} \mathrm{S}$. Invoking Ekman dynamics does not help to explain this feature

Copyright 2001 by the American Geophysical Union.

Paper number 2001GL013347.

0094-8276/01/2001GL013347\$05 00 because this belt coincides with the zero line of Ekman upwelling (Figure 1c). Figure 2a is a time-longitude section of the weekly SeaWiFS chlorophyll data averaged over $10^{\circ} \mathrm{S}$ $12^{\circ} \mathrm{S}$ for the same year. One can clearly see that the enhanced chlorophyll is propagating westward at a speed of $\sim 10 \mathrm{~km} / \mathrm{d}$. This corresponds roughly to the phase speed of the first baroclinic Rossby wave at these latitudes, suggesting that Rossby wave propagation is the cause for this chlorophyll enhancement. This notion is supported by Figure $2 \mathrm{~d}$ depicting meridional velocity derived from sea level anomaly data [Le Traon and Ogor, 1998; Le Traon et al., 1998], which also reveals wave propagation at the same phase speed. Cipollini et al. [2001] and Uz et al. [2001] used band-pass filtered data in their reports on Rossby-wave enhancement of surface chlorophyll. For the region we focus upon, the signal is so clear that no filtering of the data is required. Moreover, the data show a seasonal cycle of the surface chlorophyll enhancement. This phenomenon, i.e., enhancement of surface chlorophyll by Rossby waves with a clear seasonal cycle, is well reproduced by our biologicalphysical coupled model (Figures $1 \mathrm{~b}, 2 \mathrm{~b}, \mathrm{c}, \mathrm{e}, \mathrm{f}$ ), which will be used here to examine the mechanisms underlying the Rossby wave enhancement of surface chlorophyll and its seasonal cycle.

\section{Model results}

A detailed description of the three-dimensional biological-physical coupled model is given by Kawamiya and $\mathrm{Os}$ chlies [2001] and Oschlies and Garçon [1999]. Here we provide a brief summary of the model settings. For the physical part of the model we adopt GFDL MOM 2.1 [Pacanowski, 1995], set up for the Indian Ocean by Rix [1998]. The biological model used is nitrogen-based and has four compartments, namely, nitrate, phytoplankton, zooplankton and detritus. The horizontal resolution is $1 / 3^{\circ}$ both meridionally and zonally. There are 35 vertical levels, 10 of which are within the upper $110 \mathrm{~m}$. Monthly mean climatological data compiled by Barnier et al. [1995] are used for the wind stress, heat fluxes, sea level air temperature, and solar radiation. The physical model reveals Rossby wave propagation of meridional and vertical velocity anomalies similar to the observations (Figure 2e,f). The biological-physical coupled model is initialized with a spun-up state of the physical model plus Conkright et al. [1994] nitrate data. Results are shown for the third year of the coupled simulation.

Simulated phytoplankton abundance expressed in terms of nitrogen is compared with satellite chlorophyll observations, employing a constant conversion factor of 1.59 $\mathrm{mgChl} / \mathrm{mmolN}$. The model well reproduces the highchlorophyll belt (Figure $1 \mathrm{~b}$ ) as well as the westward propagation of individual chlorophyll anomalies (Figure 2b), albeit the width of the belt is underestimated. 
(a)

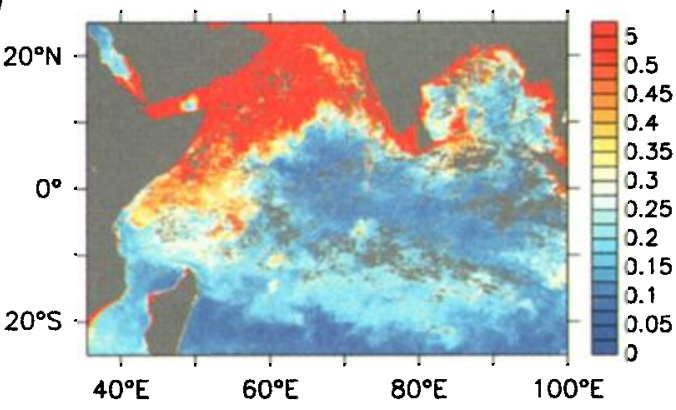

(b)

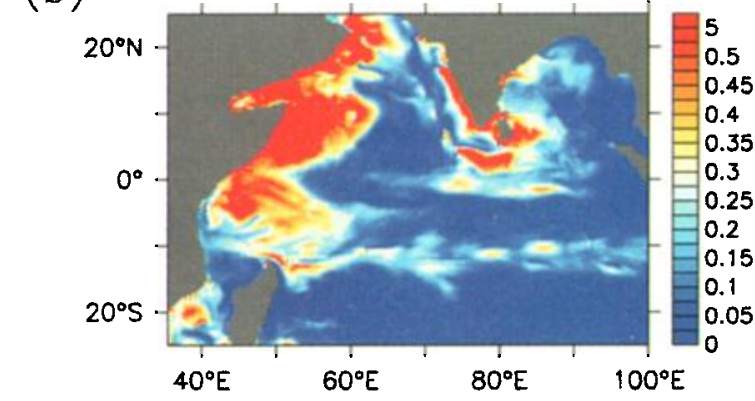

(c)

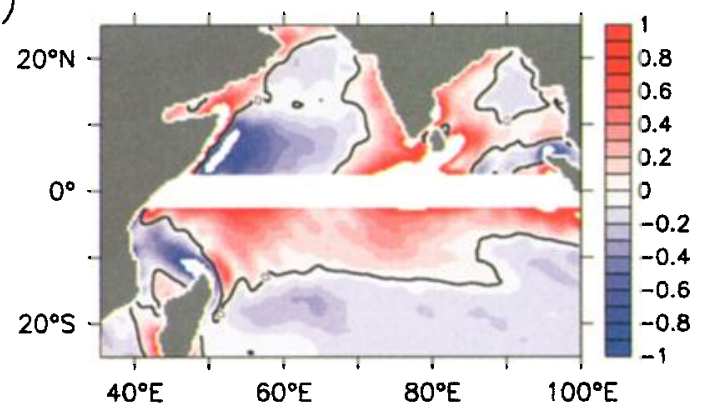

Figure 1. Monthly mean surface chlorophyll in September in $\mathrm{mg} / \mathrm{m}^{3}$ (a) measured by SeaWiFS in 1998 (b) obtained by the model under climatological forcing. The model result is averaged over the upper $20 \mathrm{~m}$. (c) Ekman upwelling in $\mathrm{m} / \mathrm{d}$ in September computed from the wind stress data Barnier et al. [1995] used also for the model forcing. SeaWiFS data are provided by the Earth Observing System Data and Information System (EOSDIS), Distributed Active Archive Center at Goddard Space Flight Center.

\section{Discussion}

In order to illustrate processes that occur during the passage of a Rossby wave, we focus on a single wave crest passing $\sim 11^{\circ} \mathrm{S}, 80^{\circ} \mathrm{E}$ on September 2, as visualized in Figures 3a,b. To identify the mechanism for the increase in surface chlorophyll, plotted in Figure 3c is the net biological source of phytoplankton, that is, the sum of the source and sink terms for biological interactions in the phytoplankton governing equation. The net biological source remains unchanged near the surface during the passage of the wave, indicating that the increase in surface chlorophyll is not caused by local phytoplankton growth stimulated by nutrient input. Indeed, Figure $3 \mathrm{~d}$ reveals no large increase in nitrate within the mixed layer (ML). Rather, the surface chlorophyll increase occurs because the ML erodes the deep chlorophyll maximum (DCM) shifted slightly upward during the passage of the wave. The uplift of the DCM is in turn brought about by upwelling (Figure 3e) through upward transport of both phytoplankton itself and nitrate. Though the light attenuation coefficient in the model is dependent on phytoplankton abundance, the euphotic zone depth (defined as the depth at which light intensity becomes $1 \%$ of its surface value) varied only within a small range $(93-96 \mathrm{~m}$ ) during the period displayed and should not be critical. Figure $3 \mathrm{f}$ shows that primary production integrated over the water column is also affected by Rossby waves. The amplitude of the fluctuation in primary production is $\sim 30 \%$ of the average over the chosen period. An amplitude of a similar extent can be found in the sinking flux of detritus (i.e., export production) across $110 \mathrm{~m}$.

It is an intriguing question whether Rossby waves have a net effect on primary production in this region, i.e., whether the increase in primary production due to the Rossby-wave induced upwelling is canceled out by the decrease due to the consequent downwelling so that the average production is the same with and without Rossby waves. One can assess the extent of cancellation by carrying out another run in which the horizontal viscosity is much enhanced so that it imitates a typical coarse resolution model [Oschlies and Garçon, 1998], thereby diminishing the activity of Rossby waves. In the third year of coupled integration from the same initial conditions as in the standard run, the resultant

(a)

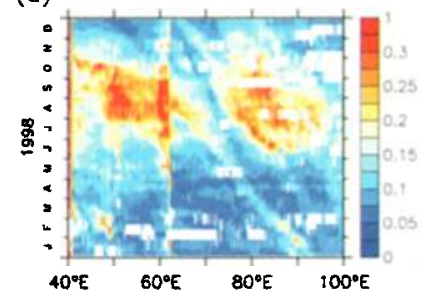

(d)

(b)

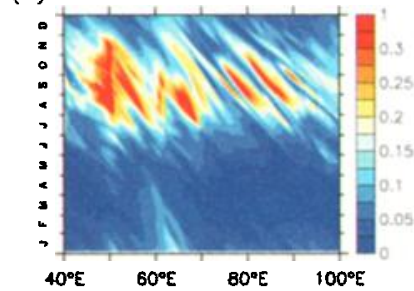

(c)

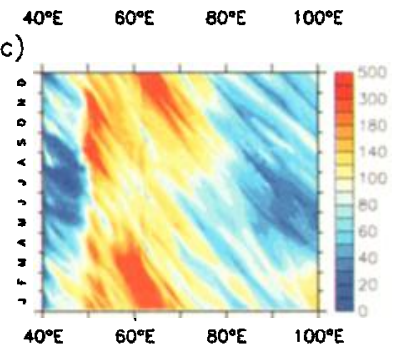

(e) (f)
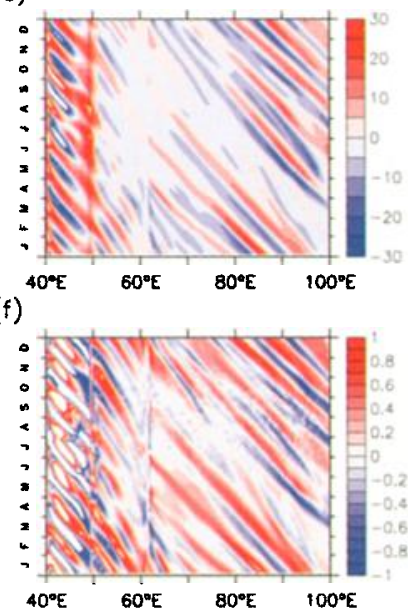

Figure 2. Hovmöller diagram of the mean over $10^{\circ} \mathrm{S}-12^{\circ} \mathrm{S}$ for surface chlorophyll in $\mathrm{mg} / \mathrm{m}^{3}$ (a) measured by SeaWiFS in 1998 (b) obtained by the model run under climatological forcing (the model result is averaged over the upper $20 \mathrm{~m}$ ), for (c) simulated primary production integrated over the upper $200 \mathrm{~m}$ in $\mathrm{mgC} /\left(\mathrm{m}^{2} \mathrm{~d}\right)$, for meridional velocity in $\mathrm{cm} / \mathrm{s}(\mathrm{d})$ derived from sea level anomaly (SLA) data measured by TOPEX/Poseidon-ERS$1 / 2$ in 1998 Le Traon and Ogor [1998]; Le Traon et al. [1998] (e) at $65 \mathrm{~m}$ in the model, and for (f) simulated vertical velocity at $70 \mathrm{~m}$ in $\mathrm{m} / \mathrm{d}$. The original SLA data are distributed with a resolution of $0.25^{\circ}$, and have been smoothed zonally with 9 point running mean. 

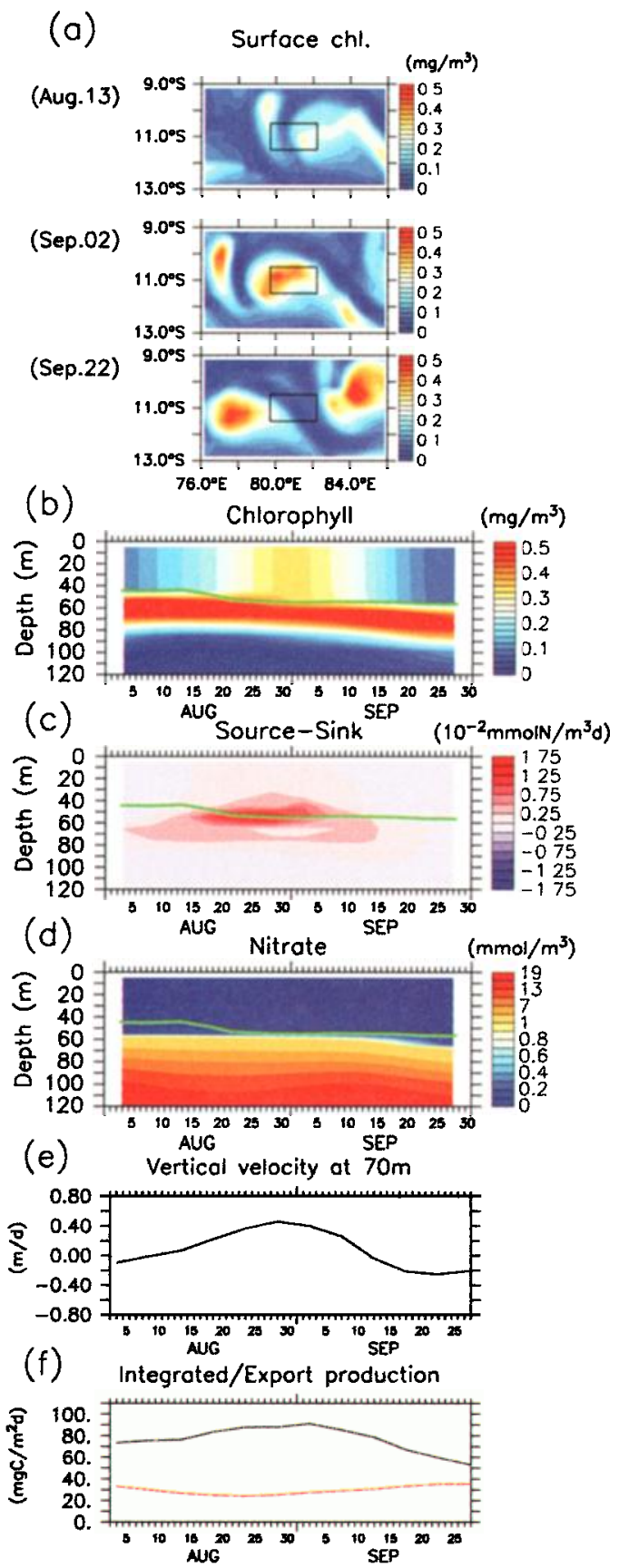

Figure 3. Detailed view on a chosen patch of enhanced chlorophyll in the model. (a) Surface chlorophyll around the patch on three dates selected from a period in austral winter, August 3 - September 27. Time-depth section for (b) chlorophyll, (c) the sum of the terms for biological interactions in the phytoplankton governing equation, and (d) nitrate. Note the difference in color shading for nitrate between the ranges above and below 1 $\mathrm{mmol} / \mathrm{m}^{3}$. The green line in b-d shows the mixed layer depth, defined as the depth of $0.1{ }^{\circ} \mathrm{C}$ temperature deviation from the surface. (e) Vertical velocity at $70 \mathrm{~m}$ depth. (f) Vertically integrated primary production (black) and export production (red) across $110 \mathrm{~m}$ depth. The time series in b-e have been averaged over the rectangle in a.

annual primary production averaged over $10^{\circ} \mathrm{S}-12^{\circ} \mathrm{S}, 40^{\circ} \mathrm{E}$ $100^{\circ} \mathrm{E}$ (the same area as displayed in Figure 2) is not much different. Rather, it is slightly $(\sim 2 \%)$ larger than in our standard simulation. Based on this model study, there is no evidence for a net increase in annual primary production by Rossby waves.

Given that the increase of surface chlorophyll through Rossby wave propagation is a passive one dependent on the phytoplankton growth near the bottom of the ML, Rossby waves can enhance primary production at subsurface depths even when it is hardly observable at the surface. Figure 2c demonstrates that vertically integrated primary production is indeed affected by Rossby waves throughout the year. In austral summer, the effect is almost invisible in surface chlorophyll because of the shallow summer $\mathrm{ML}(\sim 20 \mathrm{~m})$. At these latitudes, amplitudes of the fluctuation induced by Rossby waves are in general similar to that seen in Figure $3 f(\sim 30 \%$ of the average over one cycle) also in other seasons and places. Here we note that the Rossby wave enhancement of primary production can be found at other latitudes as well, especially in an oligotrophic region, where the ecosystem has a high sensitivity to nutrient concentration below the ML. Along $20^{\circ} \mathrm{S}$, for example, the amplitudes can reach nearly $100 \%$ of the average over a cycle, though the absolute values of primary production are much lower than those in Figure $3 \mathrm{f}$ because of the predominant downwelling throughout the year (c.f., Figure 1c).

Our model results suggest that Rossby waves have an appreciable impact on variation in primary and export production. On the other hand, the expression of associated patterns in surface chlorophyll, that in principle can be observed by satellite-mounted ocean color sensors, is controlled by the difference between the depths of the ML and DCM and does not necessarily correspond to biological production. As a consequence, integrated primary production of the model shows a seasonal cycle very different from that of surface chlorophyll (Figures 2b and c). This may impose a problem for algorithms used to estimate primary production from satellite ocean color measurements [Longhurst et al., 1995; Antoine et al., 1996; Behrenfeld and Falkowski, 1997]. A mooring system as in Tropical Atmosphere Ocean (TAO) array [Chavez et al., 1999] may be necessary to really observe the biological impact of Rossby waves.

Acknowledgments. We thank Paul Kähler for comments on the draft and Thomas Martin for processing the SeaWiFS data. FERRET was used for analyzing and displaying the model results.

\section{References}

Antoine, D., J.-M. André, and A. Morel, Oceanic primary production: 1. Adaptation of spectral light-photosynthesis model in view of application to satellite chlorophyll obsevations, Glob. Biogeochem. Cycles, 10, 43-55, 1996.

Barnier, B., L. Siefridt, and P. Marchesiello, Surface thermal boundary condition for a global ocean circulation model from a three-year climatology of ECMWF analysis, J. Mar. Syst., 6, 363-380, 1995.

Behrenfeld, M. J., and P. G. Falkowski, Photosynthetic rates derived from satellite-based chlorophyll concentration, Limnol. Oceanogr., 42, 1-20, 1997.

Chavez, F. P., P. G. Strutton, G. E. Friederich, R. A. Feely, G. C. Feldman, D. G. Foley, and M. J. McPhaden, Biological and chemical response of the equatorial Pacific Ocean to the 199798 El Niño, Science, 286, 2126-2131, 1999.

Cipollini, P., D. Cromwell, P. G. Challenor, and S. Raffaglio, Rossby waves detected in global ocean colour data, Geophys. Res. Lett., 28, 323-326, 2001. 
Conkright, M. S., S. Levitus, and T. P. Boyer, NOAA Atlas NESDIS 1: World Ocean Atlas 1994, vol.1, nutrients, Tech. rep., NODC, 1994.

Kawamiya, M., and A. Oschlies, An eddy-permitting, coupled ecosystem-circulation model of the Arabian Sea: Comparison with observations, J. Mar. Syst., submitted, 2001.

Le Traon, P.-Y., and F. Ogor, ERS-1/2 orbit error improvement using TOPEX/Poseidon: the $2 \mathrm{~cm}$ challenge, J. Geophys. Res., 103, 8045-8057, 1998.

Le Traon, P.-Y., F. Nadal, and N. Ducet, An improved mapping method of multi-satellite altimeter data, J. Atmos. Ocean. Technol., 15, 522-534, 1998.

Longhurst, A., S. Sathyendranath, T. Platt, and C. Caverhill, An estimate of global primary production in the ocean from satellite radiometer data, J. Plankton Res., 17, 1245-1271, 1995.

Mann, K. H., and J. R. N. Lazier, Dynamics of Marine Ecosystems, Blackwell Scientific Publications, Boston, 1991, 466pp.

Oschlies, A., and V. Garçon, Eddy-induced enhancement of primary production in a model of the North Atlantic Ocean, $\mathrm{Na}$ ture, 394, 266-269, 1998.
Oschlies, A., and V. Garçon, An eddy-permitting coupled physical-biological model of the North Atlantic 1. Sensitivity to advection numerics and mixed layer physics, Glob. Biogeochem. Cycles, 13, 135-160, 1999.

Pacanowski, R. C., MOM 2 documentation, user's guide and reference manual, Tech. Rep. 3, GFDL Ocean, 1995.

Rix, N. H., Investigating Indian Ocean variability in a basin scale GCM: Model assessment and model-data intercomparison, $\mathrm{Ph} . \mathrm{D}$. thesis, Universität Kiel, 1998.

Uz, B. M., J. A. Yoder, and V. Osychny, Pumping of nutrients to ocean surface waters by the action of propagating planetary waves, Nature, 409, 597-600, 2001.

M. Kawamiya, A. Oschlies, Institut für Meereskunde, Düsternbrooker Weg 20, D-24105, Kiel, Germany, (e-mail: mkawamiya@ifm.uni-kiel.de, aoschlies@ifm.uni-kiel.de)

(Received April 15, 2001; revised August 7, 2001; accepted August 15, 2001.) 